\title{
Acuerdos colectivos, justicia del trabajo y economía de guerra. Los casos de los trabajadores gráficos y tranviarios. Porto Alegre, 1942-1945
}

\author{
Collective agreements, labor justice and war economy. The cases of the \\ graphics workers and streetcar's workers of Porto Alegre, 1942-1945
}

\author{
Paula García Schneider \\ Centro de Estudios Avanzados \\ (Universidad Nacional de Córdoba) \\ paulagarciaschneider@hotmail.com
}

\section{Resumen}

La presente propuesta se enmarca en la investigación en curso implicada en mi tesis doctoral, en la cual me sumerjo en la agencia de la clase trabajadora en la ciudad brasilera de Porto Alegre entre los años 1942 y 1945. Recorte temporal definido por el ingreso de Brasil a la Segunda Guerra Mundial y la crisis del Estado Novo y apertura democrática de 1945.

Uno de los aspectos analizados en mi tesis es cómo los trabajadores, en el contexto de economía de guerra, recurren a la Justicia del Trabajo y reclaman el cumplimiento de la legislación vigente, es decir, cómo los trabajadores porto-elegrenses emplean los derechos como "armas de lucha" en el marco de recorte de la legislación laboral, hiper-explotación y carestía generalizada y especulación de alimentos. Asimismo, esperamos poder reconstruir a partir de los procesos las demandas, estrategias, pruebas, argumentos y resolución. En esta oportunidad nos proponemos analizar los procesos colectivos iniciados por el Sindicato de los trabajadores gráficos, 1942, y los tranviarios, 1945, de Porto Alegre.

\section{Palabras Claves}

Acuerdos colectivos, Justicia del Trabajo, Economía de Guerra, Trabajadores, Porto Alegre.

\section{Abstract}

This proposal is part of a ongoing research, my doctoral thesis, in which I immerse myself in the agency of the working class in the Brazilian city of Porto Alegre between 1942 and 1945. A temporal cut well defined by the entrance of Brazil to War World Two and the crisis of the Estado Novo and the Democratic Opening of 1945.

One of the issues discussed in my thesis is how workers in the context of war economy, appealed to the Labor Court and claimed compliance with current legislation, for instance, how workers porto-alegrenses used their rights as " weapons of struggle "in the context of cuts in labor laws, hiper-explotation and widespread food shortages and speculation. We also hope to reconstruct, starting from the processes, the demands involved, strategies, evidence, arguments and resolution. This time we analyze the collective proceedings initiated by the union of graphics, 1942 workers, and the streetcar, 1945, Porto Alegre.

\section{Keywords}

Collective agreements, Labor Justice, War Economy, Employees, Porto Alegre. 


\section{Presentación}

En este escrito nos proponemos examinar dos procesos colectivos iniciados por dos sindicatos de la ciudad de Porto Alegre en el Tribunal Regional del Trabajo $4^{\circ}$ (TRT $4^{\circ}$ ) de la Justicia del Trabajo uno en 1942 y otro en 19451. Para el primer caso analizaremos el acuerdo colectivo presentado por el Sindicato de los Trabajadores Gráficos de Porto Alegre en 1942. Mientras para el año 1944-1945, analizaremos la presentación judicial del Sindicato de los Trabajadores en la Empresa Carris de Porto Alegre (tranvías).

Es central aclarar que la selección de los casos está supeditada al hecho de que en el año 1943 las presentaciones colectivas de los sindicatos de trabajadores por categoría fueron derogadas por decreto presidencial. Dicha derogación se dio en el marco de la llamada estado de guerra (1942-1945) y negaba la posibilidad de presentaciones que implicaran demandas y resoluciones legales para la totalidad la categoría. Así, entre 1942 y 1945 sólo se permitían presentaciones individuales o pluri-individuales por los trabajadores o incluso a través de los sindicatos pero donde los reclamos $\mathrm{y}$, por tanto, las resoluciones de la Justicia del Trabajo únicamente tendrían efectos sobre los trabajadores demandantes, y no a todo el su sector.

Para dicha propuestas recurrimos al análisis de los procesos judiciales colectivos disponibles en el Memorial de la Justicia del Trabajo de la $4^{\circ}$ Región, Porto Alegre, Brasil.

Con el ingreso del Brasil a la Guerra Mundial en 1942, varios derechos constitucionales en general y laborales en particular fueron suspendidos. Entre ellos el derecho a acuerdo colectivo en septiembre de 1943. De esta forma, los aumentos salariales desde entonces y hasta 1945 fueron definidos a partir de decretos presidenciales y no por medio de acuerdos colectivos ${ }^{2}$.

Desde 1940 los trabajadores para solicitar aumentos salariales recurrían de manera anual a la Justicia del Trabajo, exceptuando el período 1943-1945 puesto que este derecho se encontraba suspendido según el régimen por el Estado de Guerra.

Se entiende por acuerdo colectivo al proceso dado "en el cual el poder judicial recibe la misión de solucionar un conflicto colectivo de trabajo" 3 es decir, "es por medio del acuerdo que trabajadores y empleados buscan, de común acuerdo, un resultado para cuestiones que no puedan ser solucionadas por medio de la

\footnotetext{
${ }^{1}$ Los procesos analizados aquí fueron extraídos de los microfilms disponibles en el Tribunal Regional do Trabalho da 4a Região. Memorial da Justiça do Trabalho. "Guia de consulta aos Processos de Dissídio Coletivo de Porto Alegre (1942-1966)" Digitalización realizada por Nauber Gavski da Silva. Es de mucho valor dicho trabajo y se agradece al personal del Memorial de la Justicia del Trabajo por hacer posible el acceso a esos microfilms.

${ }^{2}$ Según la tabla de salario mínimo los aumentos registrados para el periodo investigado fueron dos, uno en julio de 1943 y otro en enero de 1944.

${ }^{3} \mathrm{http}: / /$ www.infoescola.com/direito/dissidio-coletivo/ fecha de acceso 15/10/2015
} 


\section{Paula Schneider}

negociación directa, y de este hecho, atribuyen al poder judiciario la potencia para establecer la solución deseada". Estos acuerdos colectivos, se podrían iniciar tanto para resolver cuestiones económicas (salariales en su mayoría) cuanto para temas del orden jurídico.

Así, los acuerdos colectivos tenían por objetivo resolver conflictos colectivos entre trabajadores y patrones, este tipo de recurso estaba previsto en la Consolidación de las Leyes de Trabajo (CLT). Donde para definir un contrato colectivo de trabajo entre trabajadores y patrones se establecía podían hacerse presentaciones en la JT, previa consulta a sus respectivas asambleas. Según Nauber Gavski da Silva4, los sindicatos de los trabajadores generalmente hacían presentaciones anuales para recuperar la pérdida salarial en función de la inflación, lo cual era habitualmente resistido por los patrones.

En 1942 se hicieron dos presentaciones una del Sindicato de Gráficos y otra de Almaceneros. Con la apertura política de 1945, se retomaron este tipo de presentaciones en la JT, de hecho en 1945 se presentaron siete demandas por los siguientes gremios: sindicato de Carris, Teatrales y Cinematógrafos, Construcción Civil, Ebanistas, Metalúrgicos, empleados de comercio y hoteleros. En esta oportunidad, como ya dijimos, solo analizaremos dos procesos colectivos. En primer lugar, el proceso del Sindicato de los Trabajadores Gráficos Porto Alegre, fechado en 1942. Y posteriormente nos abocaremos a indagar la presentación del Sindicato de los Trabajadores en la Empresa Carris de Porto, datada en agosto de 1944 y con resolución en 1945.

En ambos casos, por un lado, se intentará mostrar las negociaciones, conflictos, estrategias y resistencias presentadas y dirimidas en la JT, tanto por trabajadores cuanto por patrones; y por otro lado, las vinculaciones posibles entre la carestía generalizada y la huelga general de 1945 con los acuerdos colectivos en estudio. Para ello prestaremos atención a dos cuestiones: a lo explicitado en los documentos, es decir: po de demanda, demandante, demandado, pruebas, argumentos y resolución. Y en un sentido más analítico, cómo se recurría a los derechos como "armas de lucha" y se apelaba a la "conciencia legal de los trabajadores". Se entiende por "conciencia legal" un modelo de conciencia de clase, donde la cultura política pasó a ser asociada a la exigencia por el cumplimiento de la CLT, pues "sirvió para moldear la demanda de los trabajadores por justicia" y para definir "un horizonte cultural común de los que debería ser dignidad y justicia en las cuestiones de trabajo"5. Así, la CLT a la vez que consolidaba la hegemonía, a través de la construcción de un corpus legal que todo lo regulaba en el ámbito laboral, también permitió el uso de esas leyes laborales por parte de los propios

\footnotetext{
4 Ver Nauber Gavski da Silva. "O "mínimo" em disputa: Salário mínimo, política, alimentação e gênero na cidade de Porto Alegre (c. 1940 - c. 1968)". Tesis de Doctorado. Universidade Federal do Rio Grande do Sul. 2014. p 55.

5 Ver: Ma. Célia Paoli. "O trabalhador urbano na fala dos outros", José Sérgio Lopes, Cultura e identidade operária: aspectos da cultura da classe trabalhadora. Ed. Marco Zero. Rio de Janeiro. 1987. John French. A legislação trabalhista brasileira: Afogados em leis, mas famintos (por justiça?). Ed. Fundação Perseu Abramo. São Paulo. 2002. p. 10.
} 
trabajadores pasara a ser parte de las estrategias de lucha de la clase, lo cual implicaba transformaciones en la organización política de los trabajadores. Así, en lo referido a la lucha por los derechos y por el cumplimiento de los deberes del Estado en la década del 30 y 40 la conciencia de clase iba a estar estrechamente vinculada al cumplimiento de las leyes laborales. ${ }^{6}$ Por tanto, parafraseando a French podríamos decir que "las leyes laborales se tornaron "reales" en los lugares de trabajo solamente en la medida en que los trabajadores lucharan para transformar la ley de un ideal imaginario en una realidad futura posible" 7

\section{El sindicato de los trabajadores industrias gráficas de Porto Alegre versus periódicos ${ }^{8}$.}

El 1 de agosto de 1942, el Sindicato de los Trabajadores Gráficos Porto Alegre presentó el proceso colectivo frente a las empresas periodísticas: S.A Diario de Noticias, Correio do Povo y Tipografía del Centro S.A. Se reclamaba el pago extra del $20 \%$ por horario nocturno. En el proceso se consigue ver la existencia de ciertas particularidades en las tareas que hacen los trabajadores de las tres empresas demandadas. Por ejemplo en el Diario de Noticias S.A se presentan 9 linotipistas $^{9}$ y 5 tipógrafos ${ }^{10}$ y ante la misma tarea o encuadrados en el mismo oficio en horario nocturno recibían diferentes remuneraciones. Asimismo, se puede ver en ese mismo periódico se presentan diferentes oficios y en su totalidad reclaman el pago por trabajo nocturno. Lo mismo ocurría en el diario Correio do Povo, pues los trabajadores con variados oficios: linotipistas, tipógrafos, mecánicos de linotipo, y su integridad reclamaban el pago del $20 \%$ extra por trabajo nocturno.

El sindicato demandante, en la presentación apelaba explícitamente al decreto ley ${ }^{\circ} 2308$ del 13 de junio de 194011. Particularmente al artículo 13 de dicho decreto. El cual establecía: el trabajo nocturno tendría una remuneración superior en un $20 \%$ sobre la hora diurna; dicha hora sería computada como 50 minutos y 30 segundos; se consideraba trabajo nocturno el ejecutado entre las 20 horas de un día y las 6 horas del día siguiente; en los horarios mixtos (que abarquen diurnos y nocturnos, como es el caso de los trabajadores gráficos) se aplicaba el $20 \%$ en las horas de trabajo nocturno y la prorrogación del trabajo nocturno se aplicaba en las actividades consideradas insalubres. Este último punto

\footnotetext{
${ }^{6}$ Ver Fernando Teixeira da Silva. A carga e a culpa. Ed. Hucitec. São Paulo. 1995. p. 102.

${ }^{7}$ John French. A legislação trabalhista brasileira: Afogados em leis, mas famintos (por justiça?), Ed. Fundação Perseu Abramo, São Paulo. 2002. p. 10.

${ }^{8}$ Proceso TRT4 371/42, fecha 08/01/1942.

${ }^{9}$ Que trabaja con una linotipia máquina que mecaniza el proceso de composición de un texto para ser impreso.

${ }^{10}$ Persona cuyo oficio es imprimir textos y dibujos el tipógrafo de la imprenta.

${ }^{11}$ Decreto-ley $\mathrm{N}^{\circ} 2.308,13$ de junio de 1940. "Dispõe sobre a duração do trabalho em quaisquer atividades privadas, salvo aquelas subordinadas a regime especial declarado em lei e dá outras providências"
} 


\section{Paula Schneider}

es relevante porque como veremos posteriormente, en el documento se hace referencia a dos cuestiones: 1) las condiciones de trabajo no son las apropiadas y 2) la falta de fiscalización por parte del Ministerio en lo que se refiere a condiciones de sanidad de los lugares de trabajo.

De esta forma, en la demanda se sostiene que desde el año 1940, cuando entra en vigencia el decreto-ley mencionado, se ejecutaban las actividades sin que las empresas (Tipográfica del Centro S.A, Diario de Noticias y Correio do Povo) cumplieran con lo dispuesto en el pago extra del 20\% sobre las horas diurnas por unidad de trabajo nocturno (que implicaba una hora de 50 minutos y 30 segundos) ${ }^{12}$.

El Sindicato de los Trabajadores en las Industrias Gráficas de Porto Alegre, demandaba: “a) reciba la presente negociación colectiva, en los términos del art. 56 y siguientes del decreto ley ${ }^{\circ} 1237$, de mayo de 193913; b) permita y determine el nombramiento de peritos a fin de averiguar el quantum de la indemnización, en los términos del Art 32 del mismo decreto ${ }^{14}$; c) se digne aceptar todo especie de pruebas, inclusive la declaración personal de las partes".

El 29 de enero de 1942, en la sala del Consejo Regional ante el presidente del Consejo de la $4^{\circ}$ Región, se realizó la audiencia inicial de instrucción del proceso. En esa primera audiencia de conciliación, se presentaron una serie de testimonios, algunos de los cuales recuperaremos a continuación a los fines de rastrear las negociaciones, las estrategias y las resistencias presentes, así como las condiciones de contratación y las condiciones de trabajo.

El primer testimonio ${ }^{15}$ fue el de Pedro Monteiro Cabral, trabajaba en el diario Correio do Povo como linotipista y por hora, el inicio de su horario era variable entre las 6, 7 y 8 en tanto la salida, siempre, era a las 3.30 horas. Además, este

\footnotetext{
12 Llamativamente el sindicato reclama el punto de un decreto fechado el 13 de junio de 1940 que había sido modificado en dos puntos el 19 de agosto de 1940, pues la duración de la hora de trabajo nocturno se prolonga unos minutos y las horas comprendidas en el horario nocturno se restringían. Esto puede ser pensado como estrategia para que los obreros trabajaran más tiempo, en duración de hora nocturna, y al comprender menos horas menos posibilidades que el trabajo realizado de noche sea efectivamente pagado con un $20 \%$ mayor.

13 Decreto-ley № 1.237, 2 de mayo de 1939. “Organiza a Justiça do Trabalho". El art 56 establecía que en los acuerdos colectivos eran competencia del presidente del tribunal o la Procuraduría del Trabajo para provocar la conciliación los empleados o sus sindicatos, los sindicatos de empresarios y, ex oficio, siempre que ocurre suspensión al trabajo. Párrafo único, en el caso que no hubiese sindicato que represente el sector profesional de los disidentes, podrá instancia conciliatoria ser provocada por un tercio de los empleados del o de los establecimientos interesados. Esto implicaba que el sindicato de los trabajadores gráficos contaba con el apoyo de sus representantes, estimamos que se explicita esta ley para que el proceso no sea desestimado por falta de representatividad de sindicato en relación a los trabajadores gráficos.

14 Decreto-ley № 1.237, 2 de mayo de 1939. “Organiza a Justiça do Trabalho”. El art 32 establecía en el proceso delante las juntas jueces y tribunal del trabajo es facultado a las partes presentar peritos o técnicos asentido el órgano juzgador. El mismo Sindicato de gráficos dem anda que la Justicia del Trabajo se haga presente en las tres empresas periodísticas demandadas a los fines de poder analizar los registros de entradas y salidas de los trabajadores gráficos para contabilizar la cantidad de horas trabajadas en horario nocturno y poder calcular el pago extra del $20 \%$ correspondiente.

15 Proceso TRT $4^{\circ} 371 / 42$, fecha 29/01/1942. Folio s/d. Las informaciones siguientes fueron extraídas del proceso.
} 


\section{Acuerdos colectivos, justicia del trabajo y economía de guerra}

trabajador planteaba que en su categoría de linotipistas, había otros trabajadores los cuales trabajaban "por línea" los cuales tienen horario de entrada pero no de salida puesto que se retiran solamente cuando cierra el expediente. También, esos operarios, sólo percibían paga cuando trabajaban y si no hubiese tareas no recibían ninguna remuneración. El salario pagado por Correio do Povo a esos linotipistas era de 19 reales por línea. Así, Monteiro Cabral alegaba que desde los diez años que trabajaba en el Correio do Povo, solo una única vez, en 1938 precio por línea era de 17 reales, fue mejorado, para 19 reales. Asimismo, testimonia que a los linotipistas diaristas, se daba media hora de descanso diario para comidas, en tanto para los que trabajaban por línea, no teniendo trabajo, para las comidas salen a la hora que quieren. Además, cuando el diario se retrasaba en ser terminado no existía ningún acuerdo entre las direcciones de diario y los empleados que trabajaban sobrepasando las 5 horas de la mañana. Asimismo, en la sección de linotipia las condiciones de salubridad eran en un término medio y no existía ni libro ni cosa semejante capaz de comprobar la entrada y la salida de los trabajadores.

De este testimonio se pueden desprender una serie de cuestiones: en primer lugar que existían dos modalidades de contratación, una por hora y otra por línea. Ello tenía efectos no sólo en los salarios recibidos por los trabajadores, puesto que los que trabajaban por línea cuando no hubiese trabajo nada recibían, sino que además los diaristas tenían regulado un tiempo para su comida, descanso y horario de entrada y salida, flexible pero relativamente constante. En tanto, los que trabajaban por línea no tenían garantizado ni salario, ni horario de refrigerio, ni de salida puesto que al ser pagos por trabajo hasta no haber sido terminada la tarea no se podían retirar del periódico. En lo referido a las horas de trabajo que superaban las 5 de la mañana, es decir horas extras no había ningún acuerdo que las regulase lo cual podría estar haciendo referencia a la falta de pago de horas extras. Finalmente queda claro la mayor parte de la jornada de trabajo de los linotipistas se realizaba durante lo que según la legislación vigente era considerado trabajo nocturno, o en horario mixto y en efecto trabajo nocturno.

Además, según el testimonio podemos entrever los funcionarios del Ministerio de Trabajo no estaban presentes en los locales de trabajo como decían estar en el discurso del Estado Novo y, sin libros que registraran la entrada y si la salida de los trabajadores pareciera ese libro era más un instrumento de control de los patrones, que una forma de dar cumplimiento a la ley en cuanto a registrar los horarios de trabajo. Consiguientemente, se dificultaba emplear esos registros como una prueba en presentaciones judiciales como la que estamos analizando.

El segundo testimonio ${ }^{16}$ es de Firmino Ferreira Alves, un trabajador con tres particularidades: la primera era su nacionalidad uruguaya y toda la justificación presente en el proceso demostrando su condición de legal. Pues recordemos que en Brasil estaba presente la ley de 2/3 la cual implicaba que en los lugares de

16 Proceso TRT $4^{\circ} 371 / 42$, fecha 29/01/1942. Folio s/d. Las informaciones siguientes fueron extraídas del proceso. 


\section{Paula Schneider}

trabajo debían ser 2/3 trabajadores de nacionalidad brasilera; la segunda característica eran sus 19 años de antigüedad; y la tercera conocía dos oficios, pues trabajó durante 1 año como tipógrafo, y 18 años como linotipista. En su declaración Ferreira Alves, en un primer momento, apela a su legalidad en el país pues dice tener 54 años de edad, ser casado con brasilera, padre de tres hijos, con cartera de trabajo. Además, declara tener 19 años de antigüedad en el diario Correio do Povo, trabajando en ese diario por segunda vez, desde el mes de octubre de 1929 y que había trabado anteriormente, desde primero de febrero de 1910 a 20 de septiembre de 1916 y agrega ratifica los dichos del primer testimonio citado en cuanto a lo pagado por el diario.

En lo referido a las diferentes tipos de contratación para los linotipistas se planteó la distinción entre contratación por hora o por línea. El criterio adoptado en cuanto a los servicios prestados para los linotipistas que trabajan por hora era el trabajo más delicado, en tanto consideraba como trabajo de obra, los que trabajaban por línea, como trabajos más simples.

En este último testimonio, al igual que los dos testimonios citados anteriormente, en lo referido al libro donde se registrarían las entradas y salidas, se planteaba la no existencia del mismo. Igualmente, se sostiene que los ingresos de los trabajadores en el periódico difieren según el día de la semana y en cuanto a la salida dependía del oficio. Los linotipistas que trabajaban por línea no tenían horario de salida. De esta forma, los trabajadores de esa sección podían ser retenidos aguardando algún trabajo el que podía o no surgir, siendo que no tuviesen trabajo no percibiría remuneración, pues sólo recibían paga cuando tuviesen trabajos a ejecutar. De esta forma, vemos que no había registro sobre entradas y salidas de los trabajadores, lo cual implica una vez más una gran dificultad o imposibilidad para saber el quantum de horas trabajadas en el Correio do Povo en horario nocturno, o en horario mixto. Además, como vimos también en los otros dos testimonios, los trabajadores linotipistas diaristas eran contratados por hora. Estos en el caso de Correio do Povo podrían salir a las 3.30 horas de la mañana o permanecer en el diario hasta cerrar la última página, lo que implicaba a veces trabajar hasta las 6 de la madrugada. Mientras los linotipistas contratados por línea, tenían una situación de trabajo peor pues no tenían horario de salida, y en el caso que no se les diera para efectuar alguna tares en particular ellos podían percibir ninguna remuneración aún permaneciendo durante horas en el lugar de trabajo.

El último y cuarto testimonio ${ }^{17}$, se desprende de la declaración datada el 30 de enero de 1942. Mario Nunes era tipógrafo, con trece años de antigüedad en el periódico Diario de Noticias. Su horario de ingreso era a las 17 horas y de salida a la 1 de la mañana, con una hora de descanso por jornada. En cuanto a la contabilización de las horas de trabajo sobre el ingreso y egreso de los trabajadores, el testimonio del trabajador decía que en el referido periódico existía

17 Proceso TRT $4^{\circ}$ 371/42, fecha 30/01/1942. Folio s/d. Las informaciones siguientes fueron extraídas del proceso. 


\section{Acuerdos colectivos, justicia del trabajo y economía de guerra}

un reloj, que había sido instalado en el año 1940, y que por ese reloj era obligación pasar para marcar el ingreso siendo que los entraban más tarde, tenían descuentos en el recibo de sueldo por el tiempo que se atrasaban. Sin embargo, cuando los empleados salían más tarde, el tiempo extra de ese trabajo no les era pago. En cuanto al reglamento sobre el horario agregaba que en las paredes de la oficina en que trabajaba existía pegado un reglamento sobre el horario de los trabajos pero tal reglamento desapareció luego de haber llegado a conocerse el aumento del 20\% referido en el decreto $\mathrm{n}^{\circ}$ 2308. Así, observamos que existió una maniobra explicita por parte de la empresa periodística para no cumplir con el pago del $20 \%$ extra por horario nocturno al ser retirado el reglamento de horarios de trabajo. Asimismo, en lo referido al control de los ingresos y no de los egresos además de evitar la contabilidad de las horas de trabajo efectivo, se imposibilitaba el pago de horas en horario nocturno y además el pago de horas extras.

Además, el declarante en cuanto a las condiciones de contratación explicita que no sólo no se cumplía con la legislación vigente en cuanto al pago de un $20 \%$ más por trabajo nocturno, sino que además en el Diario de Noticias a los trabajadores tipógrafos que trabajan en el horario diurno tenían mejores pagas por su trabajo que los nocturnos.

Más aún, cuando los linotipistas en situaciones de no tener las condiciones necesarias para realizar sus tareas sea porque aguardaban la llegada de originales para entrar en el servicio, se quedan esperando en su sección, fuera del horario de trabajo, para trabajar o si había algún desperfecto en las maquinas que necesitaba arreglos de 2 o 3 horas, los linotipistas, por orden del jefe de la Sección o de la Gerencia, no podían alejarse de sus talleres, hasta que normalizadas las maquinas, y en todos los casos los linotipistas, detenidos no percibían ninguna remuneración, porque sólo la recibía cuando producían. De esta forma, observamos que según el declarante en el Diario de Noticias los trabajadores linotipistas mas allá de las razones que imposibilitaran realizar sus tareas podían permanecer en el local de trabajo y en tanto no realizaran tareas no recibían ninguna remuneración porque su salario estaba determinado por la producción. Mientras los trabajadores gráficos diaristas fuera de horario de trabajo al aguardar trabajo si percibían remuneración de naturaleza "extra". De esta forma, una vez más debemos prestar atención a que existían dos formas de contratación bien diferenciadas, por línea o por hora, lo cual tenía implicancias directas en los salarios recibidos por cada una de los trabajadores incluidos en esas categorías.

En relación a la presencia de algún funcionario público de Dirección Regional del Trabajo en el local de trabajo, se decía ni ver ni oír de la comparecencia de ningún funcionario de la $\mathrm{D}$ - $\mathrm{R}$ del Trabajo. En relación al lugar de trabajo, el tipógrafo hace una descripción precisa sobre lo carentes que eran, pues plantea el salón donde se encontraban instaladas las oficinas de linotipia, tipografía e impresión y servicio sanitario se encontraban unidos al referido salón por 2 puertas y agregaba que en el momento de la noche, cuando hacían la quema de las matrices, (derretimiento) no pueden los empleados soportar el olor que las 


\section{Paula Schneider}

mismas arrojaban, del antimonio, y, por falta de cualquier otros aire, se veían obligados a salir para la calle, y veces las puertas se encontraban cerradas. Posteriormente, el declarante hace una breve referencia a mínimas mejorasen el local de trabajo pero estas no eran todas las necesarias a su parecer.

En este mismo proceso se relata cómo algunos trabajadores gráficos a través del sindicato ya habían intentado un acuerdo el Diario de Noticias, a los fines de cumplirse lo establecido en lo referido al aumento del 20\% para trabajo nocturno, incluso según el testimonio de este trabajador el periódico ya había prometido hacer un aumento de salarios en equidad al $20 \%$ de la referida ley, pero aún no había sido efectivizado. Además, en lo referido a remuneraciones relata el trabajador que hace 13 años cuando ingresó al periódico recibían los tipógrafos una paga diaria de 15.000 reales, y con la revolución de 1932 fueron rebajados para 14.000 reales diarios hasta 1937 cuando pasaron a recibir nuevamente la paga diaria de 16.000 reales hasta el presente, 1942. En tanto, el testigo no recuerda cuanto ganaban a los linotipistas hace 13 años, si en 1937 fue aumentado su salario diario a 18 reales por línea. Pues, no sabe si la disminución de 1932 fue generalizada. En cuanto al tiempo de descanso o alimentación los trabajadores gozan de una hora.

En este proceso también se puede ver las estrategias del abogado defensor del diario intenta desmerecer el testimonio del trabajador al plantear tres cuestiones: 1- alega que un principio elemental de la procesualidad es que en el mismo proceso ninguno es parte y testigo al mismo tiempo; 2- que el declarante ya tenía un reclamo idéntico en la $2^{\circ}$ Junta de Conciliación y Juzgamiento; y 3- ser inverosímiles las declaraciones del testigo conforme probará el tiempo. Seguidamente, este mismo abogado requirió fuese presentado el testimonio del ciudadano Pedro de Alemida Alves. Este último era un trabajador del periódico, con treinta y pocos años interrumpidamente de antigüedad. Y testificó ser "notoria la absoluta libertad para con los que trabajan, dándole hasta la impresión de una familia" más aún agrega "la empresa a la que se refiere dice no usar de intolerancia en cuanto a la entrada retrasada o la salida de sus empleados, por eso sostiene que es muy tolerante ya que los gráficos y demás empleados de las oficinas de la referida empresa, muchas veces depende de las conveniencias de los propios empleados". En lo referido a remuneraciones Alemida Alves planteaba que "los trabajadores de la tarde reciben por hora 4,50 y por línea 17 reales, en tanto los que trabajan en las horas nocturnas, perciben 5,50 y los que trabajan por línea 19 reales, considerando así, el declarante que tal forma o diversidad de salarios viene a solucionar la cuestión de los $20 \%$, exigida para el trabajo nocturno". Así, el testigo propuesto por el abogado de la empresa periodística no sólo intenta convencer con su relato sobre la "libertad" con la que se manejan en el periódico para ingresar y salir, lo que viene a intentar justificar el incumplimiento del registro en el libro de entradas y salidas, sino que además cuando hace referencia a los dos pagos diferenciales para trabajadores por hora y línea nocturnos y diurnos intenta demostrar que la legislación vigente ya estaba siendo respetada por el 


\section{Acuerdos colectivos, justicia del trabajo y economía de guerra}

Correio do Povo. En tanto, el testigo del periódico explica no saber si en relación a los pagos diferenciales del $20 \%$ por trabajo nocturno están siendo cumplidas por las otras empresas periodísticas pero sostiene que Correio do Povo era la empresa periodística que mejor pagaba a sus empleados. Asimismo, Alemida Alves decía que los tipógrafos recibían sin descuento media hora de descanso para comer, en tanto los linotipistas no gozan de este favor, porque como muchas veces llegan tardíamente, esto es, fuera de horarios. Así, observamos en este testimonio un intento por parte de la empresa y de su abogado en desacreditar y menoscabar la demanda presentada por el sindicato. Más aun, en relación al horario y tareas de trabajo dice: "Que una vez al año acostumbran ser fijados en las paredes de los talleres de CP, no carteles pero papeles prescribiendo y de forma delicada, las obligaciones a las que están sujetas en general los empleados de la empresa. Que raramente el declarante, como administrador, llama la atención en papeleta pegadas en la pared del taller para el horario a que deben obedecer los empleados, la tolerancia que a veces es hasta media hora" y "Que el horario estrictamente fijado para la entrada de los empleados es las 14 horas con salida a las 18 horas, en el turno de la noche es la entrada a las 20 horas con salida a las 4, y como ya se dijo a veces entran después del horario y salen antes, habiendo tolerancia".

Este testigo trae al tapete un tema hasta ahora ausente en los otros cuatro testimonios de los demandantes, y es el tema vacaciones lo que podría ser una estrategia para convencer al tribunal del cumplimiento de la legislación vigente por Correio do Povo. Pues, señalaba: "que la empresa desde los tiempos de su fundador, Caldas Junior, hasta hoy anualmente, gratifica a sus empleados, como cuidarle la salud concediéndole vacaciones regularmente" y más aún en relación a las condiciones de trabajo agrega dice "tanto en la parte nueva como en la antigua del edificio son buenas, dando relativo confort a los empleados" y "que una Caja de Beneficencia, denominada "Caldas Junior"18, amparaba a sus empleados en caso de enfermedad y muerte de sus familiares; y concedía prestamos. Al ir finalizando su testimonio el declarante muestra un indicio de contradicción cuando dice "finalmente en relación a la aplicación del artículo referido a trabajo nocturno y respectivo pago puede afirmar que no sabe de un entendimiento formal entre los empleados y la dirección de la empresa, no obstante... un Memorial existe".

En la audiencia de cierre de la instrucción, datada del 06 de febrero de $1942^{19}$ se encontraron los abogados de las partes implicadas y las autoridades de la Justicia del Trabajo. En dicha audiencia el abogado del sindicato señalaba "la propuesta de conciliación que ofrecía y que aceptaría era sobre el cumplimiento integral de la ley". Mientras que los abogados de cada periódico hicieron diferentes planteos. Por ejemplo el Diario de Noticias considera que "siempre cumplió la Ley de Horario Nocturno". En cuanto al diario La Nación, aducía había quedado oficialmente probado por fiscalización de la 17a Delegacia Regional que la Librería

\footnotetext{
18 Nombre de fundador del Correio do Povo.

19 Proceso TRT $4^{\circ}$ 371/42, fecha 06/02/1942. Audiencia de Cierre de Instrucción. Folio s/d. Las informaciones siguientes fueron extraídas del proceso.
} 


\section{Paula Schneider}

del Globo y la Nación ya están cumpliendo fielmente los dispositivos del Decreto Ley $n^{\circ} 2308$ viéndose desnecesaria que la reclamada Tipografía del Centro tenga que inscribir cualquier testimonio, pues la fiscalización oficial hecha por el propio Ministerio de Trabajo probaba mas que cualquier declaración de cualquier testigo. Seguidamente el presidente del Sindicato de los trabajadores comprendiendo el alcance de ese parecer, excluyó de su reclamo la Librería del Globo, lo que debería haber hecho también cuanto la Tipografía del Centro.

En tanto el abogado del diario Correio do Povo, se muestra mucho mas discrepante en su planteo, pues el Dr. Gabriel Obino decía que la empresa Correio do Povo repelía cualquier propuesta de conciliación, a fin de que el presente acuerdo sea juzgado por el Egregio Consejo Regional de Trabajo y que era un principio elemental del derecho Procesal que el peso de la prueba incumbe a quien alega. Así, una vez más el abogado de las empresas demandadas recurre al argumento que es principio procesal básico que el testimonio personal de los reclamantes por sí solo no tiene validez, y agrega que además los reclamados, las empresas periodísticas, no presentaron su defensa escrita porque los trabajadores nada probaron.

Posteriormente, los abogados hacen un planteo con claras intensiones de entorpecer el proceso, pues se pregunta si se aplica el art 13 de la ley 2308 a los trabajadores que no perciben el salario mínimo. Uno de los vocales del tribunal Temperani: vota contra el relator, por entender que el decreto se aplica a todos trabajador, independientemente de la percepción. En tanto por el presidente del tribunal, planteó tener convicción de pleno acuerdo con el voto del relator. Así, el consejo, disidió que es procedente el reclamo de los disidentes, pero, tomado por base, para el aumento del $20 \%$ pleiteados, el salario mínimo local.

El acta acuerdo recién fue firmada el 9 de abril de $1942^{20}$, y consistió en un aumento del 20\%, calculado sobre el salario mínimo y no sobre los pagos superiores. Del análisis de dicho acuerdo podemos concluir que se pretendió dejar asentado en el proceso que no se ha incumplido con la legislación vigente por parte de las empresas periodísticas y por efecto, se deduce se imposibilitaba el pedido del Sindicato de los trabajadores gráficos el pago del 20\% por trabajo nocturno en las horas ya trabajadas y fiscalizadas por el Ministerio, es decir, si no existió verificación sobre la infracción ni las empresas periodísticas incumplieron con la legislación vigente, el Ministerio de Trabajo dejó de estar presente en la relación laboral.

En el acuerdo además se especifica como "clausula" que el salario "tomando por base, para el aumento del $20 \%$ pleiteado, el salario mínimo local" pues es importante aclarar que en 1942 si bien existía un salario mínimo por ley federal aparentemente no estaba unificado en todas las regiones y estados de Brasil.

Una cuestión importante a tener en cuenta es que si bien en el proceso analizado tiene como fecha de inicio 5 de enero y el cierre con el acuerdo el 9 de

20 Proceso TRT $4^{\circ}$ 371/42, fecha 09/04/1942. Acuerdo. Folio s/d. Las informaciones siguientes fueron extraídas de las páginas comprendidas en el acuerdo. 


\section{Acuerdos colectivos, justicia del trabajo y economía de guerra}

abril de 1942, en las últimas páginas del acuerdo colectivo encontramos que en año 1945 (el 11 de junio más específicamente ${ }^{21}$ ) interviene en el proceso ya no el Consejo Regional del Trabajo como en 1942, sino el Consejo Nacional del Trabajo y en esta oportunidad se establece como acuerdo que: "no hay derecho a la percepción del adicional de $20 \%$, en tratándose de prestaciones de servicio nocturno, cuando el empleado, por fuerza del respectivo contrato de trabajo, ya perciba salario igual o superior al salario mínimo de la región acrecentado de $20 \%$, no habiendo trabajo diurno correspondiente"22

En las últimas páginas del proceso se hace referencia a que el sindicato de los gráficos hizo una nueva presentación reclamando el aumento del $20 \%$ sea sobre los ingresos y no sobre el salario mínimo. Desde esa presentación y con la intervención de la Cámara de la Justicia del Trabajo para resolver dicha controversia entre interesados, "relativa al pago del aumento del $20 \%$ sobre la remuneración del trabajador, aumento ese a ser pago de acuerdo con lo dispuesto en el art 73 de la CLT, cuando se verifica la prestación de servicio nocturno". Además, se recupera una preocupación presente anteriormente la cual plantea se debe acrecentar el 20\% el salario del empleado, es decir, "para aplicarse el porcentaje legal es necesario una base capaz de servir de apoyo a la efectivizarían del cálculo. Se debe buscar saber en qué oportunidades hay base al cálculo, esto es, en qué condiciones el salario aparece claramente definido como remuneración exclusiva del trabajo diurno, para ... entonces, deba ser acrecido de la taza porcentual atribuida, por la ley, a la remuneración del trabajo nocturno" esto es la necesidad de tener números exactos. Para ello se agrega que "de modo general el salario es la resultante del contrato de trabajo individual, y, entre nosotros, muy raramente, de contrato colectivo. El contrato individual, según la Consolidación, en su artículo 442, es así definido: "el contrato individual de trabajo es el acuerdo tácito o expreso, correspondiente a la relación de empleo". Asimismo, se sostenía en el proceso "ese acuerdo, entretanto, consonante con el art 9 de la Consolidación, es declarado nulo cuando contrario a la letra de la ley. Y no podrá tener efecto si estipula remuneraciones inferiores al salario mínimo fijado para la región, cuando se trata, es obvio, de trabajo diurno".

Para ir concluyendo, nuevamente se afirmaba que "el salario mínimo constituye, la base sobre la que se debe calcular el porcentaje de $20 \%$ a ser aumentada a la remuneración, en la hipótesis de tratarse de trabajo nocturno..." y que la Cámara de Justicia del Trabajo resolvía negar al recurso interpuesto por el Sindicato de los Trabajadores Gráficos, hasta "una vez probado que otros

\footnotetext{
${ }^{21}$ Momento posterior a febrero cuando se iniciaron nuevamente las posibilidades porque entró en vigencia nuevamente el decreto-ley que regula la presentaciones de acuerdos colectivos de trabajo en la Justicia del Trabajo.

22 Proceso TRT $4^{\circ}$ 371/42, fecha 11/06/1945. Acuerdo. Folio s/d. Las informaciones siguientes fueron extraídas de las páginas comprendidas en el acuerdo.
} 


\section{Paula Schneider}

empleados de la misma empresa, que ejercen funciones idénticas, tienen salarios iguales en trabajos diurnos"23

\section{Sindicato de los trabajadores en Empresas de Carris Urbanos de Porto Alegre versus Compañía Carris Porto Alegrense ${ }^{24}$}

Esta presentación se inició en agosto de 1944 y concluyó en mayo de 1945. Los trabajadores de la empresa Carris son los más recurrentes en los procesos individuales presentados en la JT de TRT $4^{\circ}$ a lo largo de los años investigados. Además, fue en una de las empresas que primero abandonaron los puestos de trabajo para sumándose a la huelga general de abril de 1945. Pues, a partir de la lectura de los periódicos de la época, observamos que se trataba de un sector dinámico en términos económicos, y activo en términos sindicales.

En el acuerdo colectivo se demandaba: entrega de uniforme, pago de intereses por el dinero entregado a la empresa en concepto de uniforme y devolución del dinero pagado por el mismo a la caja económica, de esta forma las demandas exceden lo salarial. Es un proceso que se resuelve rápidamente, posiblemente porque el transporte de Carris era esencial para la ciudad, pues estos trabajadores ya se habían movilizado en la huelga de 1945. Además, porque la instancia judicial si bien era un espacio de lucha por los derechos también al canalizar por vía institucional la demanda quizás fue una forma de evitar una nueva paralización del transporte en el contexto economía de guerra y de apertura democrática. Asimismo, se trató de un proceso más lineal en términos de buscar el acuerdo por parte de la compañía. Sin embargo, nótese que tiene una serie de clausulas a ser cumplidas por los trabajadores para darse cumplimiento al acuerdo. Además, este proceso en la presentación tiene además de los sellos de ingreso a la JT, un sellado con la leyenda de Urgente.

El 31 de agosto de 1944, cuando se presenta el proceso, siendo demandada la Compañía Carris, se hace la aclaración que el presidente del sindicato hace dicha presentación "usando ... las prerrogativas que le confiere el artículo $1^{\circ}$ del decretoley numero 5.821, de 16 de septiembre del año de 1943"25. El artículo referido establecía que "los acuerdos colectivos, en cuanto perdurara el estado de guerra, sólo podrán ser promovidos por los sindicatos profesionales o de empleadores, mediante previa audiencia del Ministerio de Trabajo, Industria y Comercio, que apreciará de su oportunidad". Asimismo, al inicio del proceso se cita el artículo $4^{\circ}$ el cual refería "los acuerdos colectivos pertinentes a una sola empresa o grupo industrial o comercial bajo la misma dirección, sólo podrá ser promovidos cuando por lo menos la mitad de los empleados interesados fuera asociada del sindicato profesional de origen, y la mayoría de los asociados inscriptos así el deliberar". En

\footnotetext{
23 Proceso TRT $4^{\circ}$ 371/42, fecha 11/06/1945. Rio de Janeiro. Acuerdo publicado en el diario de la Justicia el 17/07/1945.

${ }^{24}$ Proceso de negociación colectiva TRT $4^{\circ} 439 / 45 \mathrm{n}^{\circ}$ del 31/08/1944.

25 Decreto-ley $\mathrm{N}^{\circ}$ 5.821, 16 de septiembre de 1943. "Dispõe sôbre dissídio coletivo enquanto perdurar o estado de guerra".
} 


\section{Acuerdos colectivos, justicia del trabajo y economía de guerra}

el proceso se consignaba "este sindicato tiene, con un número de asociados en el total de 780, en pleno gozo de los actuales derechos sociales, conforme establece el artículo $4^{\circ}$ del mismo decreto-ley, resuelve promover el presente acuerdo colectivo contra la empresa empleadora Compañía Carris Porto Alegrense, que cuenta con el número de 1379 ejercientes de la categoría, como sus empleador" pues según ese artículo de esos 1379 trabajadores de Carris al menos 670 debían estar asociados al sindicato del sector para iniciar el proceso en la Justicia del Trabajo. De esta forma, observamos que la primera estrategia del sindicato es presentar como legal la presentación al cumplir con los requisitos legales necesarios.

Seguidamente en el proceso se introduce la demanda explicando que la empresa "reclamada Cía Carris Porto Alegrene, desde largos años, para aceptar un obrero en la profesión de conductor, conductor/chofer, fiscal, subinspector e inspector, exige como condición principal, que los candidatos entreguen en su tesorería el importe de Cr\$250 (doscientos cincuenta cruzeiros), como garantía para adquisición de uniforme, reloj, etc, abastecidos por diversos comerciantes mediante orden de aquella Cía; -que después los candidatos depositaran la cantidad, ya mencionada, es por la empleadora pasado el recibo que queda en poder del interesado, conforme documentos $\mathrm{n}^{\circ} 1$ y 2 anexos $26^{\prime \prime}$. De esta forma, se introduce la situación sobre la que se emprende la demanda pues la empresa reclamada para aceptar a un trabajador plantea como requisito este entregue a la tesorería de la empresa Cr\$25027 como garantía por uniforme, reloj, etc. elementos necesarios para iniciar el trabajo en Carris.

Así, la demanda gira en torno a una vez el trabajador fuese despedido o exonerado a este se le devolvía el importe del depósito y no los intereses de ese importe. Por tanto, al igual que en el proceso de los trabajadores gráficos, se sostiene que "la administración anterior del Sindicato demandante por intermedio de sus dirigentes por inúmeros veces buscaron, conciliatoriamente junto a la administración de la demandada hacer con que el mismo depósito del importe de las causaciones en la Caja Económica Federal de Rio Grande do Sul a fin de que ellas rindiesen intereses en beneficio de aquellos trabajadores". Más aún, se testimoniaba a pesar de las previdencias tomadas, por los dirigentes anteriores del sindicato de demandante nada consiguieron de la demandada que presentaba evasivas, alegando no poder depositar las cauciones, porque las mismas debían quedar en su poder como garantía cuando la empresa reclamada no abastece, sino que sólo da orden a los abastecedores.

Seguidamente, se apela al contrato por medio del cual la empresa accedió a la concesión del servicio, y su compromiso en abastecer de uniforme a los trabajadores de la misma empresa. Esto es: "la reclamada cuando, por intermedio

\footnotetext{
${ }^{26}$ Los anexos de este proceso igualmente que los del proceso de los trabajadores gráficos no están disponibles, posiblemente han sido destruidos.

27 En el mes de abril de 1945 cuando se hace esta presentación a la Justica del Trabajo el salario mínimo es de Cr\$380, este valor era igual desde enero de 1944 y se elevará a Cr\$ 1200 recién en enero de 1952.
} 


\section{Paula Schneider}

de la Cías Brasileras de Fuerza Eléctricas celebró contrato con la Municipalidad, en la clausula decimo octava se comprometió a abastecer al personal que sirviese en la conducción de pasajeros debidamente uniformados con una placa numerada al pecho y mayor corrección en el vestuario" pero "a pesar de los compromisos asumidos por la reclamada, jamás esta proveyó a sus empleados del uniforme por su cuenta, dando únicamente a los proveedores, que ella descuenta de los salarios de sus empleados los valores que varían de $\operatorname{Cr} \$ 15$ a 40, por mes conforme documentos 4, 5 y 6 en sobre de pago donde constan los descuentos ya mencionados". Asimismo, en la presentación el sindicato se refiere a que la empresa exigía el uso a los trabajadores pero no los proveía sin considerar "los precios carísimos de los uniformes exigidos por el reclamante, que apenas los exige pero no los provee por cuenta propia, y que del año 1939 a 1943, sufrieron una mejora aproximadamente de ciento por ciento conforme documento $n^{\circ} 7$ anexo, certificado de precio proveídos por la sastrería Maneghetti, el principal proveedor de la reclamada". Así, observamos como el encarecimiento de los uniformes en el contexto de la economía de guerra también estaban presentes en este proceso y cómo el sindicato refleja su intento por "estudiar una manera de disminuir la situación afligida de sus asociados, que ejercen sus actividades en el Departamento de Tráfico de la reclamada, y que son obligados a trabajar debidamente uniformados, con uniformes verdaderamente carísimos, que debido a su alto costo, es grande el número de trabajadores que trabajan con sus uniformes en estado desmejorado, por no poder adquirir otros, al alto costo y poca durabilidad"

Además, en la presentación analizada se planteó que antes de este proceso en la Justicia del Trabajo el sindicato tenía estipulado solicitar al Departamento Estadual de Salud, y a la empresa Carris consentimiento para sus asociados pudieran trabajar fuera de uniforme exigido, apenas con un equipo que trae la respectiva patente numerada en cuanto perdure el estado de guerra, o hasta que bajen los precios de los uniformes. Así, ante la falta respuesta del departamento de salud, el sindicato no vio otra alternativa que iniciar la demanda previa consideración de la Asamblea General del Sindicato el 30 de agosto, donde se resolvió fuese presentado el proceso "para que sea la empleadora en la forma de ley compelida a recoger a la Caja Económica Federal del Estado de Rio Grande do Sul las causaciones de todos los empleados del tráfico que las mismas retienen en su poder para que estas rindan los intereses de depósito en beneficio de estos trabajadores desde la fecha en que entregaron para los servicios de las mismas". Además, en el proceso se demanda: "sea la recurrida compelida a proveer los uniformes a los empleados del trafico o de cualquier otra sección de los cuales es exigido el uso de uniforme, conforme manda la CLT y considerando el compromiso asumido por la demandada delante la Municipalidad, esto porque lo salarios pagos por la reclamada en su mayoría o casi totalidad de sus empleados no exceden al salario mínimo de Cr\$1,85 por hora 14,80 por día 370 por mes, ${ }^{28}$ salarios estos

28 Recordemos que en ese momento el salario mínimo era de Cr \$ 370 . 


\section{Acuerdos colectivos, justicia del trabajo y economía de guerra}

que no permiten los descuentos excesivos hechos por la demandada". Esta referencia concreta al costo de los uniformes y su exigencia en el uso, y salarios que no llegan a los valores del salario mínimo nos hablan del clima de carestía y encarecimiento que vivenciaban los trabajadores de la compañía Carris en 1945.

Finalmente, la audiencia de conciliación se efectivizó el 19 de abril, después de 7 meses de iniciado el proceso, y 12 días luego de la huelga general del 7 de abril. Esta referencia a las fechas no es una apología a los datos sino es llamativo que luego de 7 meses de realizada la presentación por el Sindicato de los Trabajadores de Carris sea realizada la audiencia de conciliación a tan sólo 12 días de paralizado el transporte público de la ciudad de Porto Alegre. En la audiencia de conciliación fue leída la petición del Sindicato y sobre la misma tomó la palabra el abogado de la empresa demandada, quien presentó una propuesta de acuerdo en los siguientes términos: "según se desprende de la representación dos son las concesiones pleiteadas por el Sindicato de los Trabajadores en Empresas de Carris Urbano de Porto Alegre: A) que la Empresa fuese demandada a proveer, gratuitamente, los uniformes a los empleados de sus Departamentos de Trafico y a los de cualquier otra sección en que sea exigido el uso de uniforme b) la recaudación, a la Caja Económica, de las cauciones prestadas por los mismos empleados, a fin de estos puedan recibir los intereses correspondientes". En relación a las dos demandas el abogado propuso en cuanto a la primera parte del reclamo, teniendo en cuenta las dificultades que actualmente deparan sus empleados, se ratificaba el compromiso asumido anteriormente a la entrada del acuerdo en esta justicia especializada y según la cual acordaba en proveer a los respectivos empleados del Departamento de Trafico, gratuitamente, dos uniformes anualmente. Sin embargo, esa entrega de uniformes por parte de la compañía quedaba subordinada a las siguientes obligaciones de los empleados: 1) el uniforme debería ser usado, obligatoriamente, cuando el empleado estuviera en el ejercicio de sus funciones; 2) el empleado debería presentar el respectivo uniforme siempre completo, limpio y bien cuidado, siendo vedado usar apenas parte del mismo; 3) el uniforme sería proveído por la empleadora dentro del plazo de 2 meses, a contar de la fecha en que el empleado fuera admitido, en carácter efectivo, en el Departamento del Trafico; 4) la Compañía podría cobrar el valor del uniforme del empleado o por descuento en los pagos o en la causación en el caso que les solicite renuncia o fuera despedido por falta grave antes de transcurrido los seis mese de la fecha en que le haya sido entregado el uniforme. Estos puntos podrían ser pensados como clausulas, pues si bien es una respuesta sobre la demanda iniciada por el sindicato, la propuesta de la compañía está supeditada al cumplimiento de los 4 puntos arriba mencionados por los trabajadores. En tanto a la segunda demanda, que se refiere al pago de intereses por el dinero entregado a la empresa en concepto de "depósito" por los uniformes.

El abogado de la compañía Carris respondió que la Justicia del Trabajo era incompetente para ese tipo de demanda en vistas de ser la causación un elemento "de derecho civil, por consiguiente extraño a la legislación social. Seguidamente 


\section{Paula Schneider}

aclaró con pretensiones de "mas una vez, demostrar el respeto y a elevar consideración que siempre le merece esas benemérita Justicia, especializada" la empresa "actualmente, está estudiado la posibilidad no sólo de recoger a la Caja Económica o algún otro establecimiento de crédito, como además de restituir a ciertos empleados las cauciones exigidas de los mismos para garantizar cualquier débitos para con la Empleadora, tales como los provenientes de abastecimiento de relojes, curso de cambio, multas aplicadas a los empleados por infracciones de la Regulación Federal de Transito, etc." No obstante, el abogado se ampara en la escasez de los tiempos por lo cual todavía la demandada no podía concluir los estudios ni acordar "Caja Económica a manera de efectuar los recogimientos, por lo que requiere le sea concedido un plazo para aquel fin" hasta el 30 del mes de abril.

En esta audiencia del 19 de abril, se plasmó en el proceso el Dr. Presidente del Consejo, en virtud del completo acuerdo entre las partes, cuanto a los casos de los dos uniformes a ser dados gratuitamente a los empleados anualmente, y, aún, no cumplido los plazos del 30 de abril para la solución sobre el depósito de las causaciones resolvió que se aguarde ese plazo. Así, llegado el 2 de mayo de 1945 se declaró abierta la audiencia para el fin de ser discutido este último punto. En esa oportunidad nuevamente el abogado de la Compañía Carris Porto Alegrense, presentó la siguiente propuesta: "que la Empresa se propone a atender la pretensión del Sindicato cuando al recogimiento a la Caja Económica Federal de las cauciones prestadas por sus empleados del Tráfico" sin embargo con una serie de condiciones, estás era 1) todas las cauciones integralizadas actualmente existentes serán recogidas a la Caja Económica, en el plazo de 60 días, indispensables a la impresión de los modelos, extracción de guías, etc. pasando a rendir intereses en la conformidad del ítems tercero; 2) las causaciones aún no integralizadas o de empleados futuramente admitidos deberán ser transferidos para aquel establecimiento en el plazo de 30 días de su integralización; 3) los intereses correspondientes al valor de las cauciones serán abonados por la Caja Económica, en las condiciones que esta fije; a ningún interés directo a las causaciones aún no integralizadas o no recogidas a aquella Caja; 4) el valor de la causación será devuelto por la Compañía luego que la misma esté libre o desembarazada y después de descontado aquel débito del empleado. Los intereses serán pagos, dentro del plazo de 30 días del levantamiento de la causación, directamente por la Caja Económica, después liberada la causación y mediante orden de la Compañía a aquel establecimiento; 5) deberán ser oportunamente sustituidos todos los recibos de causación existentes en poder de los empleados, a fin de encuadrarlos en el nuevo régimen; 6) el acuerdo pasaría a vigorizar de esta fecha en adelante, no siendo admitido cualquier reclamo cuanto al pasado. En relación a esto el abogado del Sindicato de los Trabajadores en Empresas de Carris concuerda plenamente.

Así, el 7 de mayo de 1945, con el pacto de las partes el acuerdo colectivo fue homologado por el Consejo, por unanimidad de votos. El acuerdo implicaba en concreto que la Compañía Carris Porto Alegrense: A) proveyera los uniformes a los 


\section{Acuerdos colectivos, justicia del trabajo y economía de guerra}

empleados del tráfico o de cualquier otra sección que sean exigidos del uso del uniforme, y B) en la forma de la ley obligada a recoger a la Caja Económica Federal del Estado de Rió Grande do Sul las causaciones de todos los empleados de tráfico que la misma retiene en su poder para que estas rindan los intereses de depósito en beneficio de estos trabajadores desde la fecha en que entran para los servicios. Las causaciones referidas implicaban, cada una, en Cr\$250. Seguidamente se hace referencia a que será cumplido el acuerdo en tanto los trabajadores de Carris cumplan con las ya nombradas clausulas referidas. Esto es, en lo referido al uso del uniforme: sea utilizado únicamente durante el horaria de trabajo de manera obligatoria, en su totalidad y en buen estado de limpieza, será entregado por la empresa dentro de los meses de admitido en carácter efectivo y podrá ser cobrado si fuera despedido dentro de los seis meses de ser entregado el uniforme.

Finalmente el 9 de mayo de 1945 en la ciudad de Porto Alegre, en el Consejo Regional del Trabajo del Ministerio del Trabajo, Industria y Comercio, fue homologado el acuerdo entre el Sindicato de trabajadores en Empresas de Carris Urbano de Porto Alegre y la Compañía Carris Porto Alegrense.

\section{Conclusiones}

A partir, de los procesos colectivos rescatados en la JCJ $4^{\circ}$ pudimos observar cómo los abogados de los sindicatos de los trabajadores como los abogados de los patrones usaban un variado abanico de argumentos a los fines de ganar en las presentaciones judiciales. En algunos casos los patrones intentaban deslegitimar el potestad de dirimir de la Justicia del Trabajo en las cuestiones laborales. Incluso recurrían a referencias concretas para sensibilizar a los magistrados o en otros casos se intentaba demostrar que la presentación no era un acuerdo colectivo y por tanto se pedía fuera declarada improcedente la incumbencia de la Justicia del Trabajo.

Asimismo, logramos visualizar de qué forma los trabajadores, en el contexto de economía de guerra recurrían la Justicia del Trabajo, ya no sólo de forma individual sino colectiva reclamando el cumplimiento de la legislación vigente. En el caso de los gráficos reclamando por la efectivización y reconocimiento del pago del $20 \%$ extra por trabajo nocturno, y en el caso de los choferes de Carris el cumplimiento de la normativa respecto a entrega de uniformes. Pues estos dos casos seleccionados y analizados nos presentan de forma efectiva como los trabajadores defendían sus salarios en el contexto de manifiesto encarecimiento del costo de vida en el marco de la Segunda Guerra Mundial. Así, podemos afirmar que los sindicatos de los trabajadores estaban haciendo presentaciones en pos de recuperar la pérdida salarial en función de la inflación, lo cual era generalmente como vimos en los dos casos resistido por los patrones.

Por último, podemos concluir que tanto las empresas periodísticas como la empresa de transporte Carris no respetaban la legislación vigente en parte esto 


\section{Paula Schneider}

fomentado por el escaso control o inspección del Ministerio de Trabajo, lo cual nos hace pensar en cierta "complicidad" por parte del ministerio con los patrones, y en ciertas fisuras en el relato del gobierno estado-novista en la supuesta omnipresencia y omnipotencia del Estado en la regulación e intermediación de la relación laborales.

Recibido: 01/07/2015

Evaluado: $31 / 07 / 2015$

Versión Final: 29/08/2015 